\title{
Pulmonary Hemorrhage and Acute Renal Failure as an Initial Presentation of Multiple Myeloma
}

\author{
Yoshikata Morita, Mako Yasuda, Mitsushige Nakao, Yoshinori Tsujimura and Motohide Isono
}

\begin{abstract}
The combined clinical presentation of acute renal failure with pulmonary hemorrhage is known as pulmonary-renal syndrome. We describe a case of an 84-year-old woman who presented with acute renal failure and pulmonary hemorrhage at onset. Renal biopsy and bone marrow aspiration showed cast nephropathy and an abnormal increase in plasma cells, respectively. She was diagnosed with multiple myeloma and successfully treated with plasma exchange and corticosteroids. This case indicates that multiple myeloma should be considered as a cause of pulmonary-renal syndrome.
\end{abstract}

Key words: multiple myeloma, acute renal failure, pulmonary hemorrhage, pulmonary-renal syndrome

(Inter Med 49: 1401-1403, 2010)

(DOI: 10.2169/internalmedicine.49.3504)

\section{Introduction}

Multiple myeloma is a malignant plasma cell disorder characterized by anemia, monoclonal gammopathy. Since acute renal failure is a relatively common feature of multiple myeloma, it should be considered as a cause of unexplained acute renal failure (1). However, symptomatic bleeding is uncommon (2) and pulmonary hemorrhage is extremely rare. Here, we describe a patient with multiple myeloma complicated by acute renal failure and pulmonary hemorrhage without any evidence of systemic vasculitis or amyloidosis. To our knowledge this is the first case of multiple myeloma presenting as a pulmonary-renal syndrome.

\section{Case Report}

An 84-year-old Japanese woman was admitted to our hospital because of dyspnea. She was found to have renal dysfunction with proteinuria and hematuria, progressive anemia, and marked inflammatory signs. One month prior to admission she had general malaise and a 10-day history of a cough. She had been diagnosed with mild anemia 9 years previously.

On admission, her blood pressure was $132 / 52 \mathrm{mmHg}$, pulse rate was $88 / \mathrm{min}$, and her temperature was $36.8^{\circ} \mathrm{C}$. Her arterial oxygen saturation at room air was $84 \%$. She had coarse crackles in all lung fields. Laboratory tests showed the following values: serum creatinine $5.0 \mathrm{mg} / \mathrm{dL}$, blood urea nitrogen $29 \mathrm{mg} / \mathrm{dL}$, calcium $8.3 \mathrm{mg} / \mathrm{dL}$, white blood cells $8,400 / \mu \mathrm{L}$ (neutrophils $83.5 \%$, eosinophils $0.5 \%$, lymphocytes $9.0 \%$, monocytes $2.5 \%$ ), hemoglobin $5.1 \mathrm{~g} / \mathrm{dL}$, platelets $91,000 / \mu \mathrm{L}$, C-reactive protein (CRP) $10.0 \mathrm{mg} / \mathrm{dL}$, prothrombin time $12.9 \mathrm{sec}$, activated partial thromboplastin time $34 \mathrm{sec}$, Total protein $5.3 \mathrm{~g} / \mathrm{dL}$, serum albumin $2.8 \mathrm{~g} / \mathrm{dL}$, serum $\beta_{2}$-microglobulin $7.5 \mathrm{mg} / \mathrm{L}$, Immunoglobulin G 942 $\mathrm{mg} / \mathrm{dL}$, Immunoglobulin A $90 \mathrm{mg} / \mathrm{dL}$, Immuoglobulin M 8 $\mathrm{mg} / \mathrm{dL}$, and spot urine protein/creatinine ratio 2.4. There was no finding of rouleaux formation in the peripheral blood smear. Urinalysis showed $1+$ protein and $2+$ blood $(5$ to 9 cells/high-power field). Chest X-ray and computed tomography (CT) scan indicated diffuse pulmonary infiltrates in the lung (Fig. 1A, 1B). Bronchoscopic examination revealed gross bleeding, and broncho-alveolar lavage (BAL) fluid showed hemosiderin-laden macrophages. There was no evidence for pulmonary infection or plasma cell infiltration of the lung.

We initially suspected that she had pulmonary-renal syndrome due to systemic vasculitis. Therefore, we initiated a 3 -day course of plasma exchange using fresh frozen plasma (3,200 mL/cycle) and a 3-day course of intravenous methylprednisolone $(1,000 \mathrm{mg} /$ day) followed by oral prednisolone 

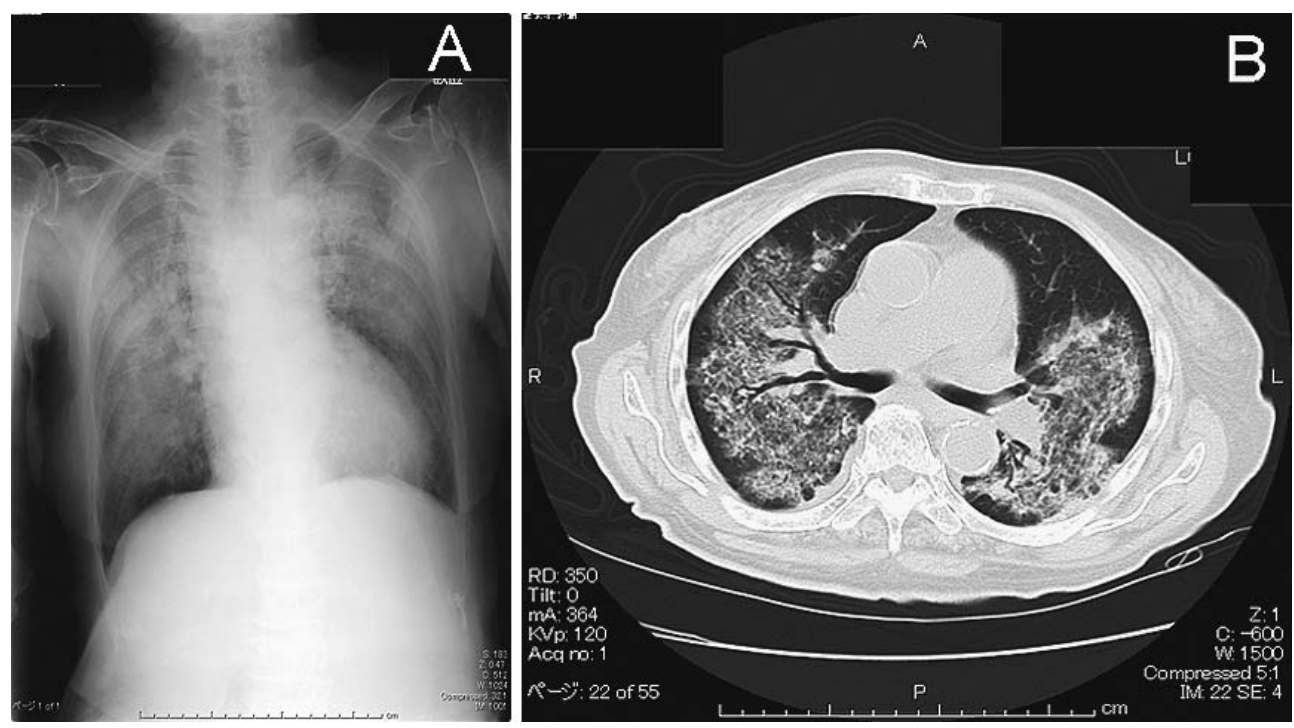

Figure 1. Chest X-ray (A) and CT scans (B) showing diffuse bilateral lung infiltrates.
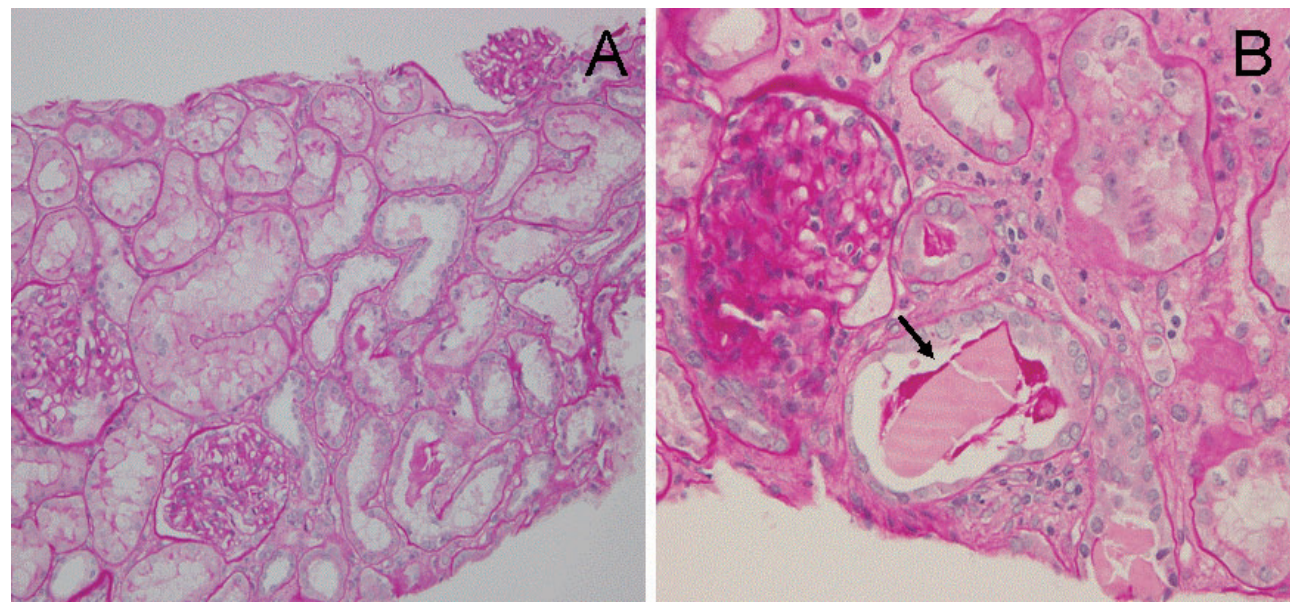

Figure 2. Light micrograph showing minor abnormalities of the glomeruli (A) and an obstructed tubule with a fractured dense cast composed of Periodic acid-Schiff (PAS)-negative immunoglobulin light chains (arrow) (B).

at $40 \mathrm{mg} /$ day. She was also treated with continuous hemodialysis due to anuria for 5 days. After these treatments, pulmonary hemorrhage rapidly diminished and renal function returned to normal. Autoantibodies including anti-nuclear antibody, anti-neutrophil cytoplasmic antibody and antiglomerular basement membrane antibody were all negative. Cryoglobulin was not detected. There was no improvement in her anemia or thrombocytopenia. Renal biopsy performed on day 10 showed that casts were present in some tubules. The glomerular compartments were almost normal in appearance although global sclerosis was seen in 2 glomeruli out of a total of 20 (Fig. 2A, 2B). Direct immunofluorescence and electron microscopy did not show any immunoglobulin deposits. These findings were compatible with cast nephropathy due to multiple myeloma. Plasma cells with abnormal morphology were increased in smear specimens of the bone marrow (more than 11 percent of total nucleated cells). The $\kappa$-type Bence Jones protein was detected by protein electrophoresis in both serum and urine. There was no evidence of amyloidosis in any tissue including the kidney, subcutaneous fat, duodenum or rectum with Congo red staining. Based on the above findings, she was diagnosed as having $\kappa$ light chain multiple myeloma with Durie/Salmon stage IIIB and International Staging System (ISS) stage III. On day 25, treatment with melphalan and prednisone was started and led to an improvement of both anemia and thrombocytopenia. Her renal function and respiratory conditions improved, and she was discharged on day 34 .

\section{Discussion}

We describe here a patient with multiple myeloma who showed acute renal failure and near-fatal pulmonary hemorrhage at initial presentation. These clinical presentations have usually been classified as part of the pulmonary-renal syndrome. The well-known causes of this syndrome are systemic vasculitis and autoimmune diseases such as microscopic polyangiitis, Wegener's granulomatosis, Goodpas- 
ture's syndrome and systemic lupus erythematosus. However, no evidence for these diseases was found in our patient.

Multiple myeloma itself is a very rare etiology of pulmonary hemorrhage. It was reported that symptomatic bleeding was present in $0 \%$ of 1,027 patients with newly diagnosed multiple myeloma (2). One of the possible causes of pulmonary hemorrhage in multiple myeloma is secondary amyloidosis. A biopsy should be taken from an organ suspected of being infiltrated with amyloid materials. If a relevant tissue sample cannot be obtained for any reason, a rectal biopsy or abdominal subcutaneous fat aspiration is recommended (1). However, there was no evidence of amyloidosis in the tissue samples from the subcutaneous fat or the rectum in our patient. Pulmonary hemorrhage without renal failure has been reported as a presenting sign for multiple myeloma in only two other cases $(3,4)$. Lung biopsy performed in these cases failed to show the accumulation of amyloid. Another cause of pulmonary hemorrhage in multiple myeloma is pulmonary infection (5), although there was no evidence of infection in the BAL fluid of our patient. In rare cases of multiple myeloma complicated by severe bleeding, paraproteins with specificity for thrombin and factor VIII have been reported (6). Thus, hemostatic abnormalities related to paraproteins might cause a bleeding diathesis in the lung of the myeloma patient.

Renal failure is a relatively common problem in patients with multiple myeloma. The acute renal failure in this set- ting is typically multifactorial. As in the present patient, myeloma cast nephropathy occurs most often in patients with high rates of production and excretion of free immunoglobulin light chains that are toxic to the tubules and can form obstructing tubular casts. Because acute renal failure and pulmonary hemorrhage are the typical presentations of a pulmonary-renal syndrome, we started plasma exchange in addition to corticosteroid therapy, resulting in the patient's successful recovery from renal failure as well as pulmonary hemorrhage. The efficacy of plasmapheresis in the management of myeloma patients presenting with acute renal failure is still controversial. Plasmapheresis has been used to rapidly reduce the plasma concentration of light chains in patients with renal insufficiency (7). Two small, prospective studies reported the improvement of renal function $(8,9)$ after plasmapheresis. On the other hand, findings from a recent large, prospective, randomized trial of plasmapheresis in the treatment of acute renal failure in 97 patients with newly diagnosed myeloma demonstrated that $30 \%$ of those who required dialysis at the onset failed to show any benefit (10).

In conclusion, we report the first case of multiple myeloma complicated by both acute renal failure and pulmonary hemorrhage presenting like pulmonary-renal syndrome. This case indicates that multiple myeloma should be added to the differential diagnosis of pulmonary-renal syndromes.

\section{References}

1. Alexanian R, Barlogie B, Dixon D. Renal failure in multiple myeloma. Pathogenesis and prognostic implications. Arch Intern Med 150: 1693-1695, 1990.

2. Kyle RA, Gertz MA, Witzig TE, et al. Review of 1027 patients with newly diagnosed multiple myeloma. Mayo Clin Proc 78: 2133, 2003.

3. Bolaman Z, Yavasoglu I, Unubol M, Kadikoylu G. Hemoptysis as a presenting sign of multiple myeloma. Respir Med 102: 1672$1673,2008$.

4. Russi E, Odermatt B, Joller-Jemelka HI, Spycher MA. Alveolar haemorrhage as a presenting feature of myeloma. Eur Respir J 6: 267-270, 1993.

5. Kintzer JS Jr, Rosenow EC 3rd, Kyle RA. Thoracic and pulmonary abnormalities in multiple myeloma. A review of 958 cases. Arch Intern Med 138: 727-730, 1978.
6. Eby CS. Bleeding and thrombosis risks in plasma cell dyscrasias. Hematology Am Soc Hematol Educ Program 158-164, 2007.

7. El-Achkar TM, Sharfuddin AA, Dominguez J. Approach to acute renal failure with multiple myeloma: role of plasmapheresis. Ther Apher Dial 9: 417-422, 2005.

8. Johnson WJ, Kyle RA, Pineda AA, O'Brien PC, Holley KE. Treatment of renal failure associated with multiple myeloma. Plasmapheresis, hemodialysis, and chemotherapy. Arch Intern Med 150: 863-869, 1990.

9. Zucchelli P, Pasquali S, Cagnoli L, Ferrari G. Controlled plasma exchange trial in acute renal failure due to multiple myeloma. Kidney Int 33: 1175-1180, 1988.

10. Clark WF, Stewart AK, Rock GA, et al. Plasma exchange when myeloma presents as acute renal failure: a randomized, controlled trial. Ann Intern Med 143: 777-784, 2005.

(C) 2010 The Japanese Society of Internal Medicine http://www.naika.or.jp/imindex.html 